Article

\title{
Perception and Attitudes of Local People on Sustainable Cultural Tourism on the Islands: The Case of Nicosia
}

\author{
Mustafa Yeniasır 1 (iD) and Burak Gökbulut ${ }^{2, *(1 D}$ \\ 1 Faculty of Education, Department of Turkish Teaching, Near East University, Nicosia 99138, North Cyprus; \\ mustafa.yeniasir@neu.edu.tr \\ 2 Faculty of Art and Science, Department of Turkish Language and Literature, Near East University, \\ Nicosia 99138, North Cyprus \\ * Correspondence: burak.gokbulut@neu.edu.tr
}

Received: 24 May 2018; Accepted: 4 June 2018; Published: 6 June 2018

\begin{abstract}
Today, for the sake of gaining tourism revenues, culture, nature and historical values are being ignored especially in island countries. As a result, tourism activities in the country decelerate and even vanish in time. According to the current tourism understanding, tourists are curious about the historical and cultural structure, which reflects the spirit of the region, and plan their travels accordingly. In this sense, it is essential that sustainable cultural tourism policies are determined by people-government-civil society cooperatively. One of the first steps of this action is to determine the opinions and attitudes of local people on sustainable cultural tourism. In this paper, Nicosia, the capital city of Cyprus, was chosen as the research area and a survey was conducted with 100 people living in this area in order to measure their perception and attitudes on sustainable cultural tourism and preservation of cultural heritage. SPSS 24.0 statistical package program was used in analyzing the obtained data. Frequency, percentage and chi-square calculations were made. Based on the results of the study, it can be claimed that an environment should be created where people of Nicosia would participate in tourism activities and some plans should be made to realize such an environment.
\end{abstract}

Keywords: North Cyprus; Nicosia; sustainability; tourism; cultural heritage

\section{Introduction}

Tourism industry is one of the indispensable sources of revenue especially for societies living on islands. In general terms, cultural tourism aims at visiting historical sites and museums, participating in the settings of local people, and tasting the traditional food in the region. Sustainable cultural tourism can be defined as tourism activities which aim at preserving natural, cultural and historical values and ensuring that future generations can also benefit from these values based on the principle of usability. In recent years, cultural tourism gained considerable importance in the globalizing world. Today people give importance to their cultural travels and pay attention to know cultures other than their own.

Tourism has three essential returns: economic, socio-cultural and environmental. It is seen that studies conducted so far have also generally focused on economic, social and environmental impacts of tourism.

"An examination of alternative tourism shows that local people, local culture, tourism industry, public administration, natural attractions and tourists are listed among the stakeholders of tourism" [1]. It is a well-known reality that people living in a region play an extremely essential role in the development and sustainability of tourism in that locality. The opinions of people on tourism and 
economic and socio-cultural development progress hand in hand and play an essential role in the formation of the society. However, tourism activities which are not well-planned by governments can lead to negative thinking about touristic activities among people who live in the region. Although tourism is an essential source of revenue especially for people living on islands, it can create some detrimental consequences if it is not managed accurately.

Varnac1, Uzun and Somuncu emphasized in their study titled "The Opinions of Local People in the Context of the Relation between Preserving Cultural Landscape and Tourism" that local people are the most essential stakeholders in areas where tourism develops: "involving local people in the development process of tourism, receiving their opinions and recommendations on this topic, trading ideas, and performing exchange of ideas in order to encourage the development of tourism in the future is essential so that local people can affect decision centers and feel themselves as a part of tourism" [2]. When the studies conducted in this area today are examined, it can be seen that the importance of local people among the mentioned stakeholders is constantly being emphasized. If the people living in a touristic country have positive views about the development of tourism, it is clear that positive developments will be experienced especially in terms of tourism activities of that country which will improve the quality of life of local people in positive direction. Thus, it can be said that the people living in that area will be freed from the negative effects of tourism.

Folklore experts can also be listed among the stakeholders of sustainable cultural tourism. In folklore studies, protecting cultural elements and transferring them to the presentation and promotion stage which is evaluated as the third dimension is critical in terms of cultural tourism [3].

The region has extreme potential for tourism with the historical buildings in the capital city of Northern Cyprus, Nicosia, and other elements which are evaluated as intangible cultural heritage [4]. Therefore, this study was conducted in the city of Nicosia where tourism activities have not reached to the desired level for a variety of reasons.

\section{Methodology of the Study}

\subsection{Objective and Questions of the Study}

The basic objective of this study is to determine the perception and attitudes of people living in Nicosia concerning cultural tourism. In addition, revealing the opinions of local people concerning tourism activities in general is also among the objectives of the study. For this purpose, in the study answer is sought to the question "what is the opinion of local people living in Nicosia concerning cultural tourism?"

The study basically sought answers to two questions and the differentiation between the opinions of participants is examined.

i According to independent variables (salary, history of residence, level of education, occupation), is there any significant difference between the opinions of participants concerning the preservation of cultural heritage in Nicosia?

ii According to independent variables (salary, history of residence, level of education, occupation), is there any significant difference between the opinions of participants concerning the development of sustainable tourism in Nicosia?

Based on the independent variables given above, it is aimed to present a hypothesis particularly concerning education status. Because of the high literacy rate and high number of university graduates in Northern Cyprus, it was expected that participants would provide positive opinions on both the preservation of cultural heritage and sustainable cultural tourism $[5,6]$. Accordingly, the hypothesis of the study is developed in Section 2.2.

Hypothesis 1 (H1). As the number of university graduates and literacy rate in Nicosia is high, it is expected that local people will provide awareness and positive opinions concerning cultural values and sustainable cultural tourism regardless of level of education. 


\subsection{Universe and Sample}

The universe of the study consists of the people living in Nicosia (Figure 1). The city of Nicosia was a deliberate choice as the research area. As the capital city of Cyprus, Nicosia has been the home of different cultures throughout history and thus accommodates several historical buildings belonging to these cultures. In addition, the only airport in Cyprus is in Nicosia and tourists who fly to the island (airway is the most widely used mode of transport) have the opportunity of seeing the city of Nicosia first. As the center of Northern Cyprus, approximately sixty five thousand people live in the city of Nicosia today. In the district of Nicosia, 77\% of the population lives in urban areas whereas $23 \%$ lives in rural areas [7] Nicosia is one of the warmest places in the country dominated by Mediterranean climate.

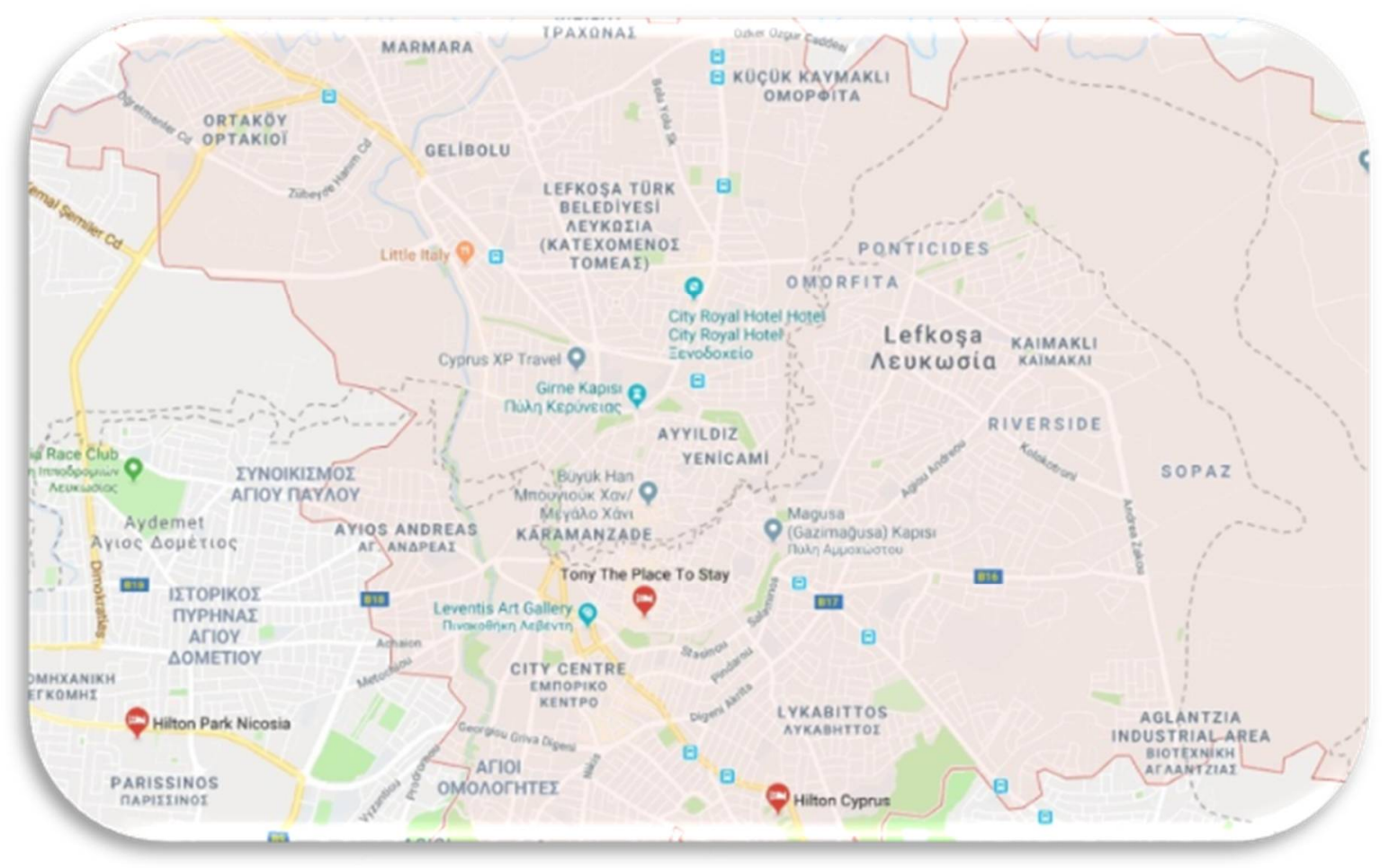

Figure 1. Research area-Nicosia.

The city of Nicosia is divided into two areas in terms of urbanization: the area within walls (old Nicosia) and the area outside walls (new Nicosia). In old Nicosia there are narrow streets and blind alleys whereas new Nicosia is spread to a broad area with wide junctions [8].

Nicosia, the capital city of Northern Cyprus, became the capital of Republic of Cyprus which was found by Greeks and Turks jointly in 1960 [9]. As the most populated city of Cyprus, Nicosia, which was home to several cultures in the past, has several monumental buildings, inns, public baths, mosques and other cultural values; however, the desired development has not been achieved in tourism. Tourists who mostly come from Turkey to the island generally prefer sea tourism for which reason they stay in Kyrenia or Famagusta. In addition to the very rich Ottoman cultural heritage all of which is the work of foundations in Nicosia, the city is also home to historical values belonging to Lusignans, Venetians and the British, all of which make Nicosia very attractive for tourists who have an appetite for cultural tourism.

Having served as the home to various cultures and civilizations, Nicosia attained a multi-cultural structure in time. This multi-cultural structure whose foundations were laid in and before Ottoman period and developed in British era is reflected on the social, physical and cultural structure of the city of Nicosia with all its aspects and created a very rich cultural and historical heritage. By this 
means, several historical buildings were built in Nicosia which were left from different periods and are stillstanding. In addition to these historical buildings, the areas and streets (Arab Ahmed Street, Samanbahçe Houses) where houses with traditional architectural style are found are also very authentic and bear historical value which reflects the social life of old times.

An examination of the historical buildings and traditional architectural structures built in Nicosia in centuries will show that they have great variety. Among the buildings in Nicosia, mosques and small mosques (Sayrayönü mosque, Arab Ahmet Mosque, Selimiye Mosque, Haydar Pasha Mosque, New Mosque, Turunçlu Mosque, Bayraktar Mosque, Araplar Mosque, Tophane small mosque), inns and public baths (the Grand Inn, Grand Public Bath, Gamblers' Inn), museums (Ethnography Museum, Mevlevi shrine, Stone Works Museum) and many more buildings (old Nicosia city walls, Kyrenia Gate, Venice Pillar, Covered Bazaar, Sultan Mahmud II Library, Aziz Efendi Lodge, Dervish Pasha Mansion, Fringed House, British Court Building, Government Building/Presidential Palace, historical houses in Arab Ahmet Street, historical houses of Samanbahçe, Bandabuliya old covered bazaar) can be listed [10]. These buildings which enrich the historical-cultural structure of Nicosia even further can be restored and preserved properly and their contribution to tourism can be increased. The attraction of the region is increased by the fact that historical and touristic buildings belonging to a variety of periods and civilizations can be found together in the city. For example, tourists who take a walk inside the walls of Nicosia can easily see the walls from Venetians, a historical-authentic house from Lusignans, an inn or a public bath from Ottomans, an old administrative building from the British, and mansions-pavilions with traditional architecture used by the people in old times during their walk, which is very attractive for a tourist. In addition, the fact that the island and thus Nicosia is at the crossroads of Eastern and Western cultures as well as Christianity and Islam religions will make sure that a tourist who comes to the region can have a unique experience. A city where mosques and churches coexist and people from different cultures live together will deliver visitors a very intriguing experience.

Although the city of Nicosia and especially the area within walls has a huge potential, the city suffers from several tourism infrastructure deficiencies. For example, accommodation/tourist hosting capacity of the city is too low and very few of the existing facilities have adequate infrastructure [11]. The mass transport network which a touristic city should have is virtually non-existent. In addition, there are few parking lots and traffic density is high. The areas where tourists can walk and ride bicycles are inadequate. All of the foregoing made imperative paying effort and creating awareness in this area. The perception and attitude of local people in this area must be evaluated, cooperation must be ensured between local and national government, and Nicosia must earn the value that it deserves.

While determining the study universe, purposive sampling technique was used in order to increase the representative power of the sample; depending on maximum diversity sampling, 100 people from different age groups, occupations and education levels were selected. Participants who were included in the study were chosen by identifying related and accessible people depending on the research question as a result of the quest for adding speed and practicality to the study. The objective here was to ensure that the results are more descriptive than generalizable. Accordingly, 100 usable questionnaire forms were obtained.

\subsection{Collection and Analysis of Data}

A questionnaire form was used in order to collect the data which would provide the basis of the study. Consisting of two sections, the questionnaire form included 14 questions prepared by researchers. After the survey questions were prepared, opinions were sought from one expert in education and another expert in tourism, and the survey was restructured based on the obtained opinions. In the first section, there are four questions on the socio-demographic characteristics of the participants (education level-occupation-salary-residence history in Nicosia). In the second section, participants were asked 10 multiple-choice questions in order to determine their perception and attitude concerning 
cultural tourism in Nicosia. The questionnaire was filled through face-to-face and in-person interviews. The questions used in the questionnaire can be grouped under three headings basically:

i Questions on what is understood from cultural heritage and its preservation,

ii Questions on the causes of expectations, positive views and problems concerning sustainable cultural tourism in Nicosia,

iii Questions on the impact of cultural heritage on sustainable cultural tourism.

In the questions of the survey, response options are presented for the participants to mark which were developed based on the literature.

SPSS 24.0 data analysis package program was used in the analysis of research data. Frequency analysis was used in the identification of socio-demographic (introductory) characteristics of the participants and obtained data were revealed with frequency distribution tables.

The opinions of participants concerning the development of tourism and preservation of cultural heritage in Nicosia depending on their introductory characteristics are given in crosstabs. In statistical comparisons, chi-square, which is employed in the comparison of two categorical variables is used.

\section{Findings and Interpretations}

In this section, 11 tables in total are given and the frequency and percentages of answers given to the questions in the questionnaire are displayed and interpreted. In addition, the distribution of participants according to socio-demographic characteristics is determined.

The viewpoint of local people who participated in the study concerning the development of tourism in Nicosia is positive at $70 \%$ level which shows that local people is willing and positive in making sustainable tourism active in the region. The ratio of people who have negative thoughts on the development of tourism in the region is $30 \%$ which is a proof that positive perceptions are at a higher level. This is a clear indicator of the public support which is critical for sustainable tourism. However, identifying the justifications of people who have negative opinions is also essential.

Table 1 presents the distribution of individuals covered in the study according to their introductory characteristics.

Table 1. Distribution of local people according to introductory information.

\begin{tabular}{lcc}
\hline Introductory Characteristics & Number (n) & Percentage (\%) \\
\hline Salary & 40 & \\
2000 TLs and below & 60 & 40.0 \\
Above 2000 TLs & & 60.0 \\
\hline Residence history in Nicosia & 20 & \\
10 years and below & 30 & 20.0 \\
11-20 years & 50 & 30.0 \\
21 years and above & & 50.0 \\
\hline Education status & 25 & \\
Elementary school & 17 & 25.0 \\
High School & 58 & 17.0 \\
University & & 58.0 \\
\hline Occupation & 25 & 25.0 \\
Worker/Farmer & 20 & 20.0 \\
Self-employed & 55 & 55.0 \\
Public official & 100 & 100.0 \\
\hline Total & & \\
\hline
\end{tabular}

An examination of Table 1 shows that $40 \%$ of the individuals included in the study have 2000 TLs and less income whereas $60 \%$ have income more than 2000 TLs. It is also found out that $20 \%$ of 
participants have been living for 10 years or less, 30\% have been living for 11-20 years and 50\% have been living for 21 years or more in Nicosia. It is determined that $25 \%$ of the participants are elementary school graduates, $17 \%$ are high school graduates and $58 \%$ are university graduates, whereas $25 \%$ are worker/farmers, $20 \%$ are self-employed and $55 \%$ are public officials.

In Table 2 an evaluation of the cultural heritage perception of the regional people who participated in the study shows that $47 \%$ evaluated traditional houses and monumental buildings as cultural heritage. On the other hand, 16\% saw traditions and customs, 15\% local food and cuisine culture and $22 \%$ saw handcrafts as cultural heritage concepts. As can be seen from the table, the most popular concept concerning cultural heritage is traditional houses and monumental buildings. Traditional houses and monumental buildings are very important in this island which has been home to several cultures throughout Cypriot Turkish history. Venetians, Lusignans, the British, Arabs, Byzantines, and Ottomans are among the civilizations that lived on the island and the houses, churches, cathedrals, mosques, palaces, inns, and covered bazaars are among the historical works of today. For example, Selimiye Mosque and Grand Inn (Figure 2) are from Ottoman era, Samanbahçe houses and courts are from British era, Venice Pillar is from Venetian era, Lusignan house (Figure 3) is from Lusignan era, all of which are very important buildings and are seen by people as very essential for sustainable cultural tourism. Local foods are also sustainable cultural tourism elements adopted and protected by the people and serve as important folkloric products which can be presented to the tourists. One of the factors that can support sustainable cultural tourism in terms of economic revenue is the making and sales of handicrafts, which also has to be mentioned among cultural heritage elements.

Table 3 gives the results of chi-square which was conducted with the purpose of comparing the opinions concerning the preservation of cultural heritage in Nicosia according to the introductory characteristics of participants.

Table 2. Cultural heritage perception of local people who participated in the study.

\begin{tabular}{lcl}
\hline \multicolumn{1}{c}{ Cultural Heritage } & Frequency & \% \\
\hline Traditional houses and & 47 & 47 \\
monumental buildings & 16 & 16 \\
Traditions and customs & 15 & 15 \\
Local food and cuisine culture & 22 & 22 \\
Handcrafts & & \\
\hline
\end{tabular}

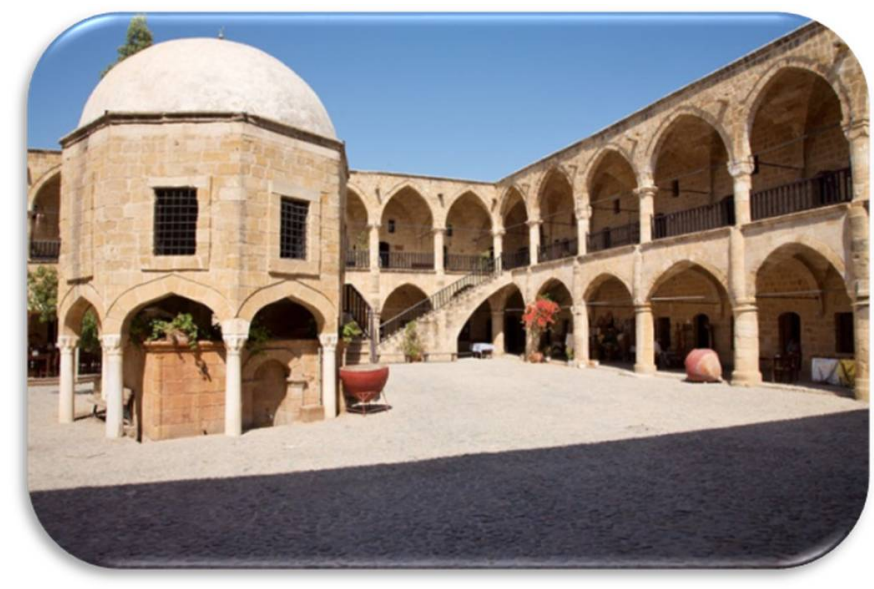

Figure 2. Grand Inn; Ottoman building constructed in 1572. 


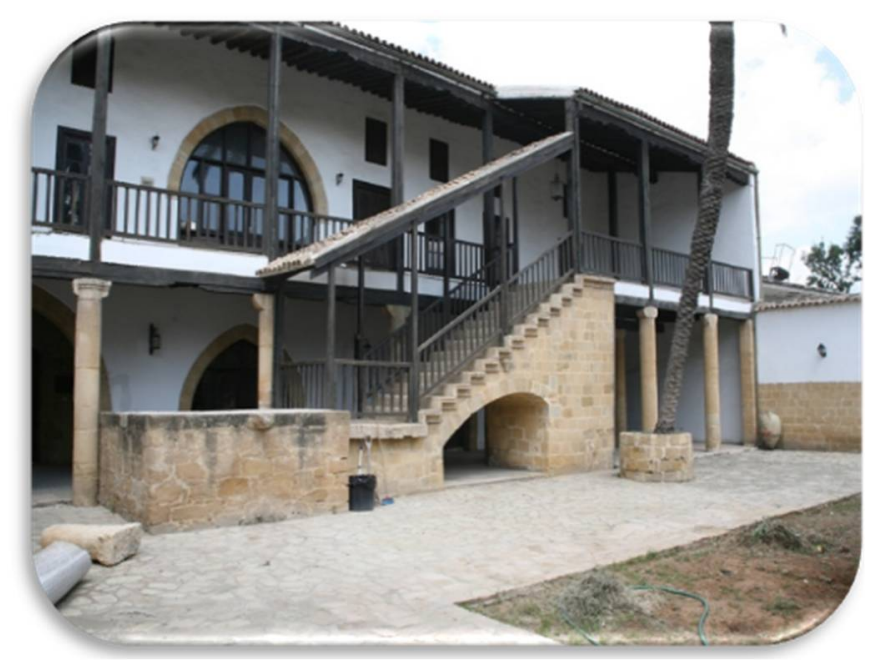

Figure 3. Lusignan House; 15th century Lusignan era building, Nicosia.

Table 3. Comparison of opinions of participants concerning the preservation of cultural heritage in Nicosia according to the introductory characteristics of participants $(n=100)$.

\begin{tabular}{|c|c|c|c|c|c|c|}
\hline & \multicolumn{6}{|c|}{ Opinion on the Preservation of Cultural Heritage in Nicosia } \\
\hline & \multicolumn{2}{|c|}{ Preserved } & \multicolumn{2}{|c|}{ Not Preserved } & \multirow{2}{*}{$X^{2}$} & \multirow{2}{*}{$p$} \\
\hline & $\mathbf{n}$ & $\%$ & n & $\%$ & & \\
\hline \multicolumn{7}{|l|}{ Salary } \\
\hline 2000 TLs and below & 35 & 87.50 & 5 & 12.50 & \multirow{2}{*}{14.835} & \multirow{2}{*}{0.000 * } \\
\hline Above 2000 TLs & 30 & 50.00 & 30 & 50.00 & & \\
\hline \multirow{2}{*}{\multicolumn{7}{|c|}{$\begin{array}{l}\text { Residence history in } \\
\text { Nicosia }\end{array}$}} \\
\hline & & & & & & \\
\hline 10 years and less & 17 & 85.00 & 3 & 15.00 & \multirow{3}{*}{10.256} & \multirow{3}{*}{$0.006^{*}$} \\
\hline 11-20 years & 23 & 76.67 & 7 & 23.33 & & \\
\hline 21 years and more & 25 & 50.00 & 25 & 50.00 & & \\
\hline \multicolumn{7}{|l|}{ Education status } \\
\hline Elementary school & 15 & 60.00 & 10 & 40.00 & \multirow{3}{*}{4.081} & \multirow{3}{*}{0.130} \\
\hline High School & 8 & 47.06 & 9 & 52.94 & & \\
\hline University & 42 & 72.41 & 16 & 27.59 & & \\
\hline \multicolumn{7}{|l|}{ Occupation } \\
\hline Worker/Farmer & 15 & 75.00 & 5 & 25.00 & \multirow{3}{*}{5.994} & \multirow{3}{*}{0.049 * } \\
\hline Self-employed & 20 & 80.00 & 5 & 20.00 & & \\
\hline Public official & 30 & 54.55 & 25 & 45.45 & & \\
\hline
\end{tabular}

An examination of Table 3 shows that $87.50 \%$ of participants with monthly income of 2000 TLs and less and 50\% of participants with monthly income more than 2000 TLs argued that cultural heritage in Nicosia was not preserved. It is seen that there is statistically significant difference between opinions of participants on the preservation of cultural heritage in Nicosia according to their monthly income and that individuals with 2000 TLs and less monthly income argue much strongly than participants with monthly income above 2000 TLs that cultural heritage in Nicosia is not preserved $(p<0.05)$.

It has been found out that $85 \%$ of participants who have been living in Nicosia for 10 years and less, $76.67 \%$ of those who have been living in Nicosia for 11-20 years and $50 \%$ of those who have been living in Nicosia for 21 years and more argued that cultural heritage in Nicosia is not preserved; thus, it is determined that there is statistically significant difference between the opinions of participants 
based on their history of residence in Nicosia $(p<0.05)$. The ratio of the argument that cultural heritage in Nicosia is not preserved is found to be higher in participants who have been living in Nicosia for 21 years and more compared to other participants.

It has been determined that there is no statistically significant difference in the argument that cultural heritage in Nicosia is not preserved according to the education level of participants $(p<0.05)$. Although the ratio of university graduate participants who argue that cultural heritage in Nicosia is not preserved is higher compared to other participants, this difference is not at a significant level.

Seventy-five per cent of the self-employed, $80 \%$ of workers /farmers and $54.55 \%$ of public officials included in the study argued that cultural heritage in Nicosia is not preserved. It has been found out that the difference in the argument that cultural heritage in Nicosia is not preserved according to occupations of participants is statistically significant $(p<0.05)$. The ratio of public official participants in arguing that cultural heritage in Nicosia is not preserved is found to be lower compared to participants in other occupational groups.

Table 4 gives the chi-square results on the comparison of opinions of participants concerning the development of tourism in Nicosia according to their introductory characteristics.

Table 4. Comparison of opinion of participants concerning the development of tourism in Nicosia according to their introductory characteristics $(n=100)$.

\begin{tabular}{|c|c|c|c|c|c|c|}
\hline & \multicolumn{6}{|c|}{ Opinion on the Development of Tourism in Nicosia } \\
\hline & \multicolumn{2}{|c|}{ Positive } & \multicolumn{2}{|c|}{ Negative } & \multirow{2}{*}{$X^{2}$} & \multirow{2}{*}{$p$} \\
\hline & $\mathbf{n}$ & $\%$ & $\mathrm{n}$ & $\%$ & & \\
\hline \multicolumn{7}{|l|}{ Salary } \\
\hline 2000 TLs and below & 34 & 85.00 & 6 & 15.00 & \multirow[b]{2}{*}{7.143} & \multirow[b]{2}{*}{0.008 * } \\
\hline Above 2000 TLs & 36 & 60.00 & 24 & 40.00 & & \\
\hline \multicolumn{7}{|c|}{ Residence history in Nicosia } \\
\hline 10 years and less & 17 & 85.00 & 3 & 15.00 & \multirow{3}{*}{3.000} & \multirow{3}{*}{0.223} \\
\hline $11-20$ years & 21 & 70.00 & 9 & 30.00 & & \\
\hline 21 years and more & 32 & 64.00 & 18 & 36.00 & & \\
\hline \multicolumn{7}{|l|}{ Education status } \\
\hline Elementary school & 22 & 88.00 & 3 & 12.00 & \multirow{3}{*}{8.669} & \multirow{3}{*}{0.013 * } \\
\hline High School & 14 & 82.35 & 3 & 17.65 & & \\
\hline University & 34 & 58.62 & 24 & 41.38 & & \\
\hline \multicolumn{7}{|l|}{ Occupation } \\
\hline Worker/Farmer & 10 & 50.00 & 10 & 50.00 & \multirow{3}{*}{4.779} & \multirow{3}{*}{0.092} \\
\hline Self-employed & 19 & 76.00 & 6 & 24.00 & & \\
\hline Public official & 41 & 74.55 & 14 & 25.45 & & \\
\hline
\end{tabular}

It has been found out that $85 \%$ of individuals with 2000 TLs and less monthly income had positive opinions and $15 \%$ had negative opinions on the development of tourism in Nicosia. On the contrary, $60 \%$ of individuals with more than 2000 TLs income have positive opinions and $40 \%$ have negative opinions. It has been found out that there is statistically significant difference between the opinions of participants concerning the development of tourism in Nicosia according to their monthly income level and that people with income over 2000 TLs have more negative opinions concerning the development of tourism in Nicosia compared to people with income below 2000 TLs $(p<0.05)$.

It has been found out that there is no statistically significant difference between opinions of participants concerning the development of tourism in Nicosia according to their history of residence in Nicosia $(p>0.05)$.

It has been found out that $88 \%$ of elementary school graduate participants, $82.35 \%$ of high school graduate participants and $58.62 \%$ of university graduate participants have positive opinions concerning the development of tourism in Nicosia. It has also been determined that there is statistically 
significant difference between opinions of participants concerning the development of tourism in Nicosia according to their education level $(p<0.05)$. It has been identified that university graduates have positive opinions concerning the development of tourism in Nicosia at a significantly lower level compared to other participants.

It has been found out that there is no statistically significant difference between the opinions of participants concerning the development of tourism in Nicosia according to their occupation $(p>0.05)$.

In Table 5 an evaluation of the expectations of local people who have positive views about tourism shows that the highest expectation is about the increase in income level of Nicosia in particular and TRNC in general (45\%) and that financial concerns are in the first place. The second highest expectation is about opening of new workplaces $(13 \%)$ which is also related to financial concerns. The third-ranking concern is about raising awareness on cultural values (10\%) which is an important topic, but it is in the lower ranks of expectations list. Nicosia to become a modern world city was pronounced by only $2 \%$ of the local people which can be due to the fact that this target is seen as too high and unattainable.

Table 5. Expectations of local people from tourism who have positive opinions about tourism.

\begin{tabular}{lcc}
\hline \multicolumn{1}{c}{ Expectations } & Frequency & $\%$ \\
\hline Increase in the income level of Nicosia in particular and Northern Cyprus in general & 45 & 45 \\
Raising awareness about cultural values & 10 & 10 \\
Opening of new work places in the region & 13 & 13 \\
Nicosia to become a modern world city & 2 & 2 \\
\hline
\end{tabular}

As can be seen in Table 6, thirty per cent of the local people who participated in the questionnaire presented negative opinions about the development of tourism. Five per cent of the participants thought that tourism would not bring any benefits to the local people and tradesmen, $12 \%$ believed that huge economic spending would be needed for the development of tourism and $13 \%$ objected development of tourism due to the concerns that demographic and socio-cultural structure of the city of Nicosia could be distorted. The most striking of the problems mentioned by local people is the belief that demographic and socio-cultural structure of Nicosia would be distorted. In this sense, it is imperative that tourists take into consideration the characteristics of the visited country during their stay in the region. Generally the tourist flow is from developed countries to less developed countries, and if these tourists do not act carefully, due to their social interaction with local people, they spread the culture of their home country which leads to some negative results. Therefore, the opinions of local people should be consulted and these concerns should be eliminated.

Table 6. The reasons indicated by participants with negative opinions towards the development of tourism.

\begin{tabular}{lcc}
\hline Reasons & Frequency & \% \\
\hline Development of tourism will bring no benefits to the regional people and tradesmen & 5 \\
Huge economic spending is needed for restoring cultural heritage and make it viable for tourism & 12 & 12 \\
I think that the demographic and socio-cultural structure of Nicosia will be distorted & 13 & 13 \\
\hline
\end{tabular}

Nevertheless, although it is true that huge spending is needed to restore cultural heritage and make it viable for tourism, it is clear that it will yield more returns due to the touristic and cultural activities that can be generated thereafter. Five per cent of the people of Nicosia who participated in the study believed that tourism would bring no benefit to the local people and tradesmen, which is not relevant. It cannot be denied that sustainable touristic cultural activities create benefits for the local people and tradesmen. In this sense realities should be explained to the people.

As can be seen in Table 7, thirty-five per cent of the people who presented a positive view stated that if tourism developed, historical buildings in the city would have improved appearances, $10 \%$ claimed that sensitiveness would be created towards cultural values, $15 \%$ stated that handcrafts would 
be recognized in the world, and 10\% asserted that cuisine culture would be revived further. Based on the evaluation of the responses it can be claimed that each are consistent within themselves and that the mentioned positive impacts can be observed if tourism is developed in Nicosia.

Table 7. Positive impact areas of protection of cultural heritage in Nicosia.

\begin{tabular}{lcc}
\hline \multicolumn{1}{c}{ Positive İmpact Areas } & Frequency & \% \\
\hline The appearance of historical buildings in Nicosia & 35 & 35 \\
Sensitiveness towards cultural values & 10 & 10 \\
Promotion of handcrafts in the world & 15 & 15 \\
Revival of cuisine culture & 10 & 10 \\
\hline
\end{tabular}

Considering that island countries need tourism, support given to tourism is as important as the viewpoint towards tourism by the local people. An examination of Table 8 shows that seventy per cent of the local people who participated in the questionnaire supported tourism as they thought that it was vital, whereas $30 \%$ did not support tourism, as they believed that touristic activities were not important for Northern Cyprus and Nicosia.

Table 8. Distribution of the opinions of local people who participated in the questionnaire concerning giving support.

\begin{tabular}{lrr}
\hline Opinions Concerning Supporting Tourism & Frequency & $\%$ \\
\hline I will support as I think that it bears vital importance & 70 & 70 \\
I do not support as I do not think that touristic activities are very important for Northern Cyprus and Nicosia & 30 & 30 \\
\hline
\end{tabular}

It is extremely essential that sustainable cultural tourism is supported by the local people and that local people take active part and pay effort in the mentioned touristic activities. In this context, people of Nicosia who stated that they could support tourism were asked what they could do to support and interesting answers were obtained in Table 9: $25 \%$ of the local people said that they could open boutique hotels conforming to the spirit of the region, $10 \%$ said that they could make contribution with handcrafts and handworks, $15 \%$ said that they could open restaurants which would promote and popularize traditional Cypriot Turkish cuisine, $10 \%$ said that they could organize festivals and seminars to promote traditional culture and another $10 \%$ said that they would deliver seminars and conferences to promote traditional culture.

Table 9. Types of support mentioned by individuals who stated that they could give support to tourism.

\begin{tabular}{lcc}
\hline \multicolumn{1}{c}{ Types of Support } & Frequency & \% \\
\hline Opening boutique hotels conforming to the spirit of the region & 25 & 25 \\
Making contribution with handcrafts and handworks & 10 & 10 \\
Opening restaurants which introduce and popularize traditional Cypriot Turkish cuisine & 15 & 15 \\
Organizing festivals and shows which can promote traditional culture & 10 & 10 \\
Delivering conferences and seminars that promote traditional culture & 10 \\
\hline
\end{tabular}

All of the answers given by people living in Nicosia to this question indicate the actions that have to be taken in order to elevate cultural tourism in the city to a more advanced level.

An examination of Table 10 shows that in Northern Cyprus, $77 \%$ of the local people have entirely negative opinions about the contribution of the government in sustainable cultural tourism activities in Nicosia. Seventy-seven per cent of the people living in the region think that the government absolutely does not pay adequate effort in the preservation of cultural heritage and popularization of tourism in Nicosia whereas $12 \%$ of the local people believe that government pays little effort in the preservation of cultural heritage and popularization of tourism in Nicosia. Eleven per cent stated that what the government does in this area is adequate. 
Table 10. Do you think that government activities concerning sustainable cultural tourism in Nicosia are adequate?

\begin{tabular}{lcc}
\hline \multicolumn{1}{c}{ Whether they Find Government Activities Concerning the Issue Adequate or Not } & Frequency & $\%$ \\
\hline $\begin{array}{l}\text { Government absolutely does not pay adequate effort in the preservation of cultural } \\
\text { heritage and popularization of tourism in Nicosia }\end{array}$ & 77 & 77 \\
$\begin{array}{l}\text { Government pays little effort in the preservation of cultural heritage and popularization of } \\
\text { tourism in Nicosia }\end{array}$ & 12 & 12 \\
$\begin{array}{l}\text { Government has a master plan for sustainable cultural heritage and tourism in Nicosia } \\
\text { and it is becoming better every day }\end{array}$ & 11 & 11 \\
\hline
\end{tabular}

It is remarkable that $77 \%$ of the people living in Nicosia think that the efforts paid by the government for sustainable cultural tourism activities are inadequate. It is an essential indicator that government has to pay more effort to elevate cultural activities in the region to a higher level. Besim et al. stated that considering the importance of tourism industry for TRNC which has island economy, it is seen that the allocations from public budget for tourism industry are at negligible level which shows that government does not provide adequate support in this area [12].

The answers of participants of the study as regards whether they find adequate the sustainable cultural tourism activities of non-governmental activities in Nicosia are evaluated in Table 11. Accordingly, $65 \%$ of the people underline that civil society organizations are performing no activities for sustainable cultural tourism in Nicosia. The ratio of people who stated that non-governmental organizations made little contribution in this area is $25 \%$ whereas only $10 \%$ think that the activities of non-governmental organizations in this area are adequate.

Table 11. Do you think that the efforts paid by non-governmental organizations (NGOs) in sustainable cultural tourism activities in Nicosia are adequate?

\begin{tabular}{lcc}
\hline \multicolumn{1}{c}{ Opinions Concerning the Activities of NGOs } & Frequency & $\%$ \\
\hline No, NGOs are making no contribution to cultural tourism in Nicosia. & 65 & 65 \\
NGOs are making little contribution to tourism and preservation of cultural heritage in Nicosia. & 25 & 25 \\
NGOs are making adequate contribution to tourism and protection of cultural heritage in Nicosia. & 10 & 10 \\
\hline
\end{tabular}

It is imperative that non-governmental organizations make contribution to the activities aiming at elevating especially sustainable cultural tourism in an area to adequate level. An evaluation of the opinions of people living in Nicosia in this area shows that non-governmental organizations are far from being adequate in this respect.

\section{Discussion}

In this study, the attitude and opinions of local people concerning the popularization of sustainable cultural tourism in Nicosia are determined and it was observed that people have positive opinions concerning the development of cultural tourism in the region. Based on this study, a sustainable cultural tourism plan can be developed in accordance with the attitude and opinions of the local people. To obtain sustainable cultural tourism, involving local people in tourism planning and organization processes can create a positive impact. Uzun and Somuncu state that including people in tourism processes and seeking their opinion would make them feel as a part of tourism and create a positive impact [2]. According to Meimand et al., it is possible to develop more sustainable tourism strategies based on the preferences of local people [13].

In the study, most of the local people presented positive views about the development of tourism in the region and supported tourism in such respects that income level of Nicosia could increase, more work places could be opened in the region and awareness could be raised about cultural values. From this perspective, developing plans to ensure that tourism increases income level in the region and activating these plans by preserving cultural heritage are among the steps that should be taken. The support of local people is inevitable in order for cultural tourism to develop in a region because the 
most important factor which produces cultural activities and ensures their continuity is the local people. According to Henkel et al., the regional image of local people is essential in supporting the development of tourism as well as ensuring sustainability [14]. Likewise, Gürsoy et al. thinks that sustainability of the development of tourism requires public support [15]. In some studies, it is stated that the positive attitude is the result of the fact that tourism provides economics benefits for the region and the people [2]. Some other studies conclude that tourism is evaluated positively due to its economic contributions [16-18].

Considering the hypothesis of the study (see H1), the importance of education in providing a positive opinion is addressed. According to the hypothesis, due to high literacy and university graduation rates, it is expected that local people would be knowledgeable about cultural values and sustainable cultural tourism and state positive opinions and the importance of education is discussed. In his study, Akova stated that local people presented positive opinions towards tourism regardless of education level [5]. On the other hand, Aygün claimed that education is the most important factor in the process of preserving cultural heritage [6].

The biggest concerns of those who have negative views about the development of tourism in the region are that tourism will not make any financial contribution to the local people or tradesmen, that a huge economic spending is needed in order to restore cultural heritage and make it viable for tourism, and that demographic and socio-cultural structure of Nicosia will be distorted. In their study, Meimand et al. indicate that several researchers have emphasized the benefits of tourism for economic development which led to the relative negligence of its social and cultural impacts [13]. Açıcı agrees with this opinion and claims that "considering the existing economic facilities of public administration and local governments and the existing legislations, it is clear that hundreds of years of efforts and a very high level of funding is needed in order to complete scientific excavations and restorations" [19].

Based on the foregoing, at the stage of developing and popularizing cultural tourism, people should be enlightened that economic interest and returns will be profitable and the people with negative opinions should be persuaded. In addition, taking into consideration the rightful concerns of people claiming that demographic and socio-cultural structure of Nicosia would be distorted, a sustainable cultural tourism master plan should be prepared. While preparing these plans, protection of social and cultural structure of the region should not be neglected. Damaging the socio-cultural structure and historical buildings in the region will also give harm to tourism because, according to some studies, most tourists think that architectural heritage sources are the most attractive sites in the places they visit [20]. This means that a tourist visiting to a certain location wants to see the traditional and historical architecture in that area. In addition, sustainable tourism emphasizes responsible utilization of economic, socio-cultural and environmental sources for the development of tourism [21]. For this reason, the social and cultural elements that are especially emphasized in this study should be taken into consideration for the positive attitude of regional people and for sustainable cultural tourism. As a result, the opinions of people with negative views must be paid attention and they should be given education in this subject. According to Akova, if the people affected by the economic, social, cultural and environmental changes created by tourism develop a negative perception and attitude towards this development, the progress of tourism will be interrupted which can create an environment that can discomfort tourists. For this reason, the researcher claims that informing on this kind of attitudes and measuring the perception and attitude of local people in regular intervals would be useful [5].

It is also essential that individuals who stated that they would support tourism are promoted by the government in areas where they will give this support. One of the most fundamental objectives of tourism policies is the development and sustainability of tourism industry. Therefore, encouragement and protection of tourism industry is the responsibility of government sector. The government must encourage tourism industry within several facilities [22]. This support will ensure that local people can participate in sustainable cultural tourism more easily. For example, people who want to open boutique hotels or restaurants where traditional food will be sold could be supported with low-interest 
loans and people who want to produce handcrafts can be given government support which will increase the participation of local people and sustainability. From this perspective, the monetary and project-based support of the government is critical in the development of tourism.

Some studies argue that people who have lived for a long time in a certain region are expected to make more sustainable contribution to the region and develop a more positive attitude towards tourism. For example, Davis et al. argued that people who live in a region for a longer time have more positive attitude towards tourism compared to people who live for a shorter period [23]. Jurowski et al. claimed that people who live in a region for a long time have positive perceptions about tourism in social and economic terms [24]. However, this study indicated no significant difference depending on the history of residence.

In addition to being touristic destinations, islands have unique geographical, socio-cultural and economic characteristics, which make islands attractive but also fragile and vulnerable. Islands have become shore-sea tourism-oriented touristic destinations, and the automatically developing tourism can create serious pressure on the destination and detrimental environmental, socio-economic and cultural consequences. For this reason, concrete plans and models are needed which will ensure the satisfaction of visitors and minimize the negative impacts and the damage to resources of all kinds [25]. This is also the case for Cyprus island in general and Nicosia in particular. It is observed that the fragile structure of the island (especially some negative results of the high number of people coming from Turkey who prefer shore-sea tourism) has partial effects on tourism activities in Nicosia. In this sense, concrete plans and models are also needed for Nicosia.

The fact that high quality and comfortable travel to Cyprus can only be made through airway and that using sea transportation effectively is not possible is another important and unique deficiency [12]. In addition, the under population of the island can be seen as a threat by people in cases when number of tourists increases gradually, which is also partly the case for the local people of Nicosia. It can be stated that especially long-staying visitors of the island create this situation. The long-staying visitors of Nicosia are foreign students at the universities of the city. The attitude of some of the local people towards perpetual and continuous tourists can sometimes be negative. It is observed that local people are concerned about the potential changes and degeneration in the demographic and socio-cultural structure of the region due to the constant decrease of the ratio of local people compared to the ratio of tourists and even the outnumbering of local population by tourists. This impression was obtained in the face-to-face interviews which were held in order to conduct the questionnaire. This means that although tourism can have positive results in general, it can create some negative results in less developed societies. As Baykan stated, "tourism is a phenomenon which affects people and societies, and can also be affected by people and societies. Tourists are affected by the lives of people of the places they visit; on the other hand, local people can be affected by the life styles of tourists and tend to live like them, which can create both positive and negative results on the local life" [26].

\section{Conclusions}

Tourism activities have considerable importance for island communities. However, if necessary measures are not taken for the development of tourism in a region, unfavorable results can be generated for local people. Unless necessary measures are not taken parallel to the development of tourism, people who are affected by the economic, social and environmental changes in the region will have a negative perception of the development and thus touristic activities will be interrupted. Therefore, the perception and attitude of local people have to be known so that sustainable cultural tourism activities can continue their positive development.

Nicosia, which is the capital city of Northern Cyprus, has outstanding historical and cultural values as Cyprus island was home to several cultures in the past (the civilizations which lived on the island in history: Assyrians, Phoenicians, Hittites, Persians, Ancient Greeks, Memluks, Egyptians, Genevans, Venetians, British, Lusignans, Ottomans, etc.). However, evaluations show that tourist figures of the region have not reached the desirable level. 
In this study, it was seen that the perception and attitudes of local people living in the city of Nicosia concerning sustainable cultural tourism activities is considerably positive (70\%). This study also found out that $30 \%$ of the local people developed negative attitudes towards sustainable cultural tourism activities. One of the reasons displayed by those with a negative approach is their belief that the demographic and socio-cultural structure of the city of Nicosia would be distorted. Based on this point made by the local people, competent folklorists and sociologists must perform studies and measures must be taken to prevent the foregoing from happening.

The study concluded that local people believed that cultural heritage in Nicosia is not preserved. Seventy-seven per cent of the people living in Nicosia think that government activities as regards sustainable cultural tourism are not adequate. In addition, $65 \%$ of the local people think that the activities of non-governmental organizations are also insufficient.

It is observed that the most important expectation of local people from tourism is economic. Forty-five per cent of the local people believe that their income level will increase with cultural activities. Another $13 \%$ think that new workplaces will be opened as a result of such cultural activities. It was found out that people who stated that they could make contribution to tourism activities mostly wanted to open boutique hotels conforming to the spirit of the region (25\%). In addition, $10 \%$ stated that they could make contribution with handcrafts and handworks, $15 \%$ stated that they could open restaurants which promote and popularize Cypriot Turkish cuisine, and another 10\% said that they could deliver seminars and conferences which would promote traditional culture. However, it would be unfounded to claim that all of the people of Nicosia who participated in the questionnaire are sufficiently knowledgeable about this topic.

An evaluation of the cultural heritage perception of the local people who participated in the study shows that $47 \%$ consider monumental buildings and houses, $16 \%$ consider traditions and customs, $15 \%$ consider cuisine culture and $22 \%$ consider handcrafts as cultural heritage.

One of the most remarkable findings of the study is that people with less than 2000 TLs monthly income has more positive attitude towards sustainable cultural development compared to people with more than 2000 TLs monthly income.

This study suffers from some limitations on the exploration of opinions of local people concerning tourism activities. Especially while determining the study universe, purposive sampling method is used in order to increase the representative power of the universe and 100 people in total from different age groups, occupations and education levels are chosen; however, it should be born in mind that if the mentioned study group is extended further (which requires a much longer time) the results can change in this context, too. The questionnaire is applied not in isolated places but in real life environment; thus, it should be remembered that there could be some factors in action which could affect the responses (such as time limitations and consulting with peers for some questions). The prepared survey consisted of two sections and 14 questions in total based on expert opinions. In the first section, four variables through which demographic information would be obtained on the participants were focused, whereas in the second section 10 questions were asked to measure the perception and attitude of local people living in Nicosia on cultural tourism. In future studies different variables and questions can be prepared and the perception and attitude of local people concerning cultural tourism can be evaluated from different perspectives. The questions in the questionnaire were evaluated separately and the data collection tool was not named as "scale". Based on the findings of this research, it can be said that a standardized scale which is validated and verified can be developed.

Despite all these limitations, it is believed that this study can be accepted as a valuable and strong research on the sustainability of cultural tourism especially in islands.

\section{Recommendations}

i Based on these findings, it is necessary that an environment should be created for local people for their involvement in tourism activities in the city of Nicosia where sustainable cultural tourism activities are not adequately developed and some planning in this direction is needed so that the 
cultural heritage values in the region can be preserved more consciously and tourism activities can develop further. It should be remembered that in a country or city where tourism activities are perceived negatively by the local people, development of tourism and adequate preservation of cultural heritage is not possible.

ii The government should use its organizing power and financial means and ensure that cultural products are produced and architectural and other cultural elements are preserved in cooperation with the public; thus, it should contribute to the sustainability of cultural tourism.

iii Civil society organizations can organize activities which involve local people in sustainable cultural tourism activities and act with the local people in this direction which can create a shared synergy and shift the people in negative side to the positive side.

Author Contributions: The article was written by both researchers. B.G. collected the data and M.Y. analyzed it. B.G. focused on the parts of introduction, methodology section and limitations; M.Y. wrote findings, discussion, conclusion and suggestions parts of the research.

Conflicts of Interest: The authors declare no conflict of interest.

\section{References}

1. Baytok, A.; Pelit, E.; Soybalı, H.H. Is it alternative tourism or diversity in tourism? A conceptual evaluation. Erzincan Univ. J. Soc. Sci. Inst. 2017, ÖS-IV,1-14.

2. Uzun, F.V.; Somuncu, M. The opinions of local people in the context of relations between cultural landscape protection and tourism: Case of Ihlara Valley. Ankara Univ. J. Ecol. Sci. 2011, 3, 21-36.

3. Ekici, M. Third dimension in folklore studies. Millî Folkor (Natl. Folklore) 2003, 15, 72-77.

4. Smith, L.; Akagawa, N. Intangible Heritage; Routledge: London, UK, 2009.

5. Akova, O. A study on the perception and attitudes of local people on tourism. J. Acad. Stud. 2006, 1. Available online: http:// dergipark.ulakbim.gov.tr/akademikincelemeler/article/view/5000067776 (accessed on 5 Jun 2018).

6. Aygün, H.M. Participatory in protecting cultural heritage. J. Found. 2011, 35, 191-213.

7. Atasoy, A. Kuzey Kıbrıs Türk Cumhuriyeti'nin Nüfus Coğrafyası/Population Geography of Turkish Republic of Northern Cyprus. Mustafa Kemal Univ. J. Soc. Sci. Grad. Sch. 2011, 8, $29-62$.

8. Mor, A.; Çitçi, M.D. KKTC'de Kentleşme/Urbanization in Cyprus. J. Eastern Geogr. 2007, 12, $225-245$.

9. Caner, G. Multiculturalism, Division and Planning: Lessons for Urban Integration and the Case of Nicosia. Ph.D Thesis, Istanbul Technical University, Maslak, Istanbul, Turkey, 2014.

10. Karabulut, Y. Tourism in Turkish Republic of Northern Cyprus. DTCF J. 2017, 32, 209-235.

11. Prime Ministry State Planning Organization Statistics and Research Department. TRNC Statistical Annal; TRNC State Printing Office: Nicosia, Cyprus, 2017.

12. Besim, M.; Sertoğlu, K.; Tanova, C.; Sevin, U.; Fethi, S.; Sıla, İ.; Ekici, T.; Küçük, N. Stable and Sustainable Economic Growth in Turkish Republic of Northern Cyprus: A Sector-Based Analysis and Policy Recommendations. Available online: http:/ /i-rep.emu.edu.tr:8080/xmlui/handle/11129/1890 (accessed on 22 May 2018).

13. Meimand, S.E.; Khalifah, Z.; Zavadskas, E.K.; Mardani, A.; Najafipour, A.A.; Ahmad, U.N.U. Residents' Attitude toward Tourism Development: A Sociocultural Perspective. Sustainability 2017, 9, 1170. [CrossRef]

14. Henkel, R.; Henkel, P.; Agrusa, W.; Agrusa, J.; Tanner, J. Thailand as a tourist destination: Perceptions of international visitors and Thai residents. Asia Pac. J. Tour. Res. 2006, 11, 269-287. [CrossRef]

15. Gürsoy, D.; Chi, G.C.; Dyer, P. Locals' attidutes toward mass and alternative tourism: The case of Sunshine Coast, Australia. J. Travel Res. 2010, 49, 381-394. [CrossRef]

16. Korça, K. Resident perceptions of tourism in a resort town. Leisure Sci. (Taylor Fr.) 1998, 20, $193-212$. [CrossRef]

17. Raymond, C.; Brown, G. A spatial method for assessing resident and visitor attitudes towards tourism growth and development. J. Sustain. Tour. 2007, 15, 520-540. [CrossRef]

18. Zhang, J.; Inbakaran, R.J.; Jackson, M.S. Understanding community attitudes towards tourism and host-guest interaction in the urban-rural border region. Tour. Geogr. 2006, 8, 182-204. [CrossRef] 
19. Açıcı, F.K.; Ertaş, Ş.; Sönmez, E. Sustainable Tourism: Cultural tourism and cultural heritage. Akademia Interdiscip. Sci. Stud. J. 2017, 3, 52-66.

20. Gholitabar, S.; Alipour, H.; Costa, C.M.M.D. An Empirical Investigation of Architectural Heritage Management Implications for Tourism: The Case of Portugal. Sustainability 2018, 10, 93. [CrossRef]

21. Kunasekaran, P.; Gill, S.S.; Ramachandran, S.; Shuib, A.; Baum, T.; Herman Mohammad Afandi, S. Measuring sustainable indigenous tourism indicators: A case of Mah Meri Ethnic Group in Carey Island, Malaysia. Sustainability 2017, 9, 1256. [CrossRef]

22. Toker, B. Evaluation of tourism industry incentives in Turkey. Yönetim ve Ekonomi (Manag. Econ.) 2007, 14, 81-92.

23. Davis, D.; Allen, J.; Cosenza, R.M. Segmenting local residents by their attitudes, interest and opinions toward tourism. J. Travel Res. 1988, 27, 2-8. [CrossRef]

24. Jurowski, C.; Uysal, M.; Williams, D.R. A Theoretical Analysis of Host Community Resident Reaction to Tourism. J. Travel Res. 1997, 34, 3-11. [CrossRef]

25. Doğan, M.; Gümüş, M. Sustainable destination management, sustainable Tenedos: A model proposal. J. Travel Hotel Manag. 2014, 11, 6-25.

26. Baykan, E. An Application on the Perception of the Impact of Tourism on Local Culture by Local People. Unpublished Master's Thesis, Gazi University Graduate School of Education Sciences, Ankara, Turkey, 2007.

(C) 2018 by the authors. Licensee MDPI, Basel, Switzerland. This article is an open access article distributed under the terms and conditions of the Creative Commons Attribution (CC BY) license (http:/ / creativecommons.org/licenses/by/4.0/). 